\title{
Synergistic curative effect of chicory extract and cisplatin against thioacetamide-induced hepatocellular carcinoma
}

\author{
Hanaa A. Hassan'1, Hanaa M. Serag', Nabil M. Abdel-Hamid², Mahmoud M. Amr' \\ ${ }^{1}$ Department of Zoology, Division of Physiology, Faculty of Science, Mansoura University, Mansoura 35516, Egypt \\ ${ }^{2}$ Biochemistry Department, Pharmacy College, Kafr El-Sheikh University, Kafr El-Sheikh 33516, Egypt
}

\begin{abstract}
Aim: Hepatocellular carcinoma (HCC) is the dominant form of primary liver cancer and is histologically and etiologically distinct from other forms of primary liver cancer. The objective of this study was to elucidate the synergistic effect and the role of chicory extract [inulin (IN)] as a chemo-sensitizer for cisplatin (CIS) treatment of HCC. Methods: Five groups of rats were treated for 4 months. These groups consisted of the control group, a group receiving thioacetamide (TAA) (200 mg/kg b.w) in drinking water, a group injected intraperitoneally with a single dose of CIS (7.5 mg/kg b.w) in addition to TAA for 4 months, a group receiving oral doses of IN (10 mg/kg b.w) in addition to TAA for 4 months, and a group injected intraperitoneally with a single dose of CIS ( $7.5 \mathrm{mg} / \mathrm{kg}$ b.w) and IN (10 mg/kg b.w) plus TAA for 4 months. Results: The current data exhibited increment of serum and liver enzyme (alanine aminotransferase, aspartate aminotransferase, alkaline phosphatase, creatine kinase, and lactate dehydrogenase) activity, serum lipid profile levels (total lipids, total cholesterol, triglycerides, low-density lipoprotein, and very low-density lipoprotein), and a significant increase in $\alpha$-fetoprotein and bilirubin, accompanied with reduced total serum protein and albumin levels in a HCC rat model. Histopathologically, numerous alterations were detected in hepatic tissues of HCC rats, such as lymphocytic cell infiltration, damage of hepatocytes, dilated congested central vein with degenerated endothelial cells, and congested blood sinusoids in addition to Masson's trichrome staining blue collagen fibers in hepatocytes and central vein indicating hepatic fibrosis. Treatment of HCC rats with CIS or IN improved such deleterious effects, where IN is more effective than $\mathrm{CIS}$, and the best effect can be observed in rats that received both CIS and IN. Conclusion: It could be concluded that IN in chicory extract acts as a chemo-sensitizer to CIS for treatment in an $\mathrm{HCC}$ rat model.
\end{abstract}

Key words: Chicory; cisplatin; hepatocellular carcinoma; inulin

Address for correspondence:

Dr. Hanaa A. Hassan, Department of Zoology, Division of Physiology, Faculty of Science, Mansoura University, Mansoura 35516 , Egypt. E-mail: drhanaahassan@yahoo.com

Received: 03-07-2015, Accepted: 23-09-2015

\section{INTRODUCTION}

Cancer is one of the most anxiety-inducing diseases and it is presenting with further prolongation and increasing occurrence. ${ }^{[1]}$ The most common and recurrent primary malignancy of the liver is recognized as hepatocellular

\begin{tabular}{|l|c|}
\hline \multicolumn{2}{|c|}{ Access this article online } \\
\hline \multirow{2}{*}{ Website: } & Quick Response Code \\
http://www.hrjournal.net/ & \\
DOI: & \\
10.4103/2394-5079.167376 & \\
&
\end{tabular}

carcinoma (HCC), a major malignancy worldwide and is increasingly associated with cancer-related death. ${ }^{[2]}$ HCC represents the most common primary malignancy of the liver. According to epidemiological surveys, the prevalence

This is an open access article distributed under the terms of the Creative Commons Attribution-NonCommercial-ShareAlike 3.0 License, which allows others to remix, tweak, and build upon the work non-commercially, as long as the author is credited and the new creations are licensed under the identical terms.

For reprints contact: reprints @medknow.com

How to cite this article: Hassan HA, Serag HM, Abdel-Hamid NM, Amr MM. Synergistic curative effect of chicory extract and cisplatin against thioacetamide-induced hepatocellular carcinoma. Hepatoma Res 2015;1:147-54. 
of HCC ranks sixth among all cancers. Under normal physiologic conditions, the liver ensures homeostasis of lipid and lipoprotein metabolism. ${ }^{[1]}$ Accordingly, hepatic cellular damage impairs liver function and can lead to alterations in lipid metabolism, and subsequently, may play a vital role in the development of HCC. Moreover, lipids are also involved in cellular signaling. In particular, lysophosphatidic acid is a powerful cellular signaling agent and acts as a potent mitogenic molecule. ${ }^{[1]}$ However, according to recent reports, the incidence of HCC has increased sharply in the last decade, especially in Egypt, where there has been a doubling of the incidence rate during the last 10 years. This sharp rise has been attributed to several factors including hepatitis $\mathrm{B}$ and $\mathrm{C}$ virus infections, endemic infections in the community as schistosomiasis, as well as environmental factors. ${ }^{\left[{ }^{[3]}\right.}$ Cisplatin (CIS) is extensively used as a chemotherapeutic agent for the treatment of HCC. A major problem with CIS treatment of HCC is the development of CIS chemoresistance. ${ }^{[4]}$ Revealing the underlying mechanism for the development of chemoresistance is indispensable for developing effective chemotherapeutic agents. ${ }^{[4]}$ Cellular proliferation, an important prerequisite for tumorigenesis, imparts metabolic challenges. ${ }^{|5|}$ The constant doubling of proteins and lipids requires uptake of nutrients in excess of that normally required. In addition to increasing nutrient uptake, proliferating cells also increase metabolic pathways to support biosynthesis. ${ }^{|6|}$ Chicory (Cichorium intybus $L$.) is one of the most promising novel candidates among carbohydrates with potential for both nutrient and non-nutrient utilization. It has been implemented in folk medicine from North Africa to South Asia for more than 100 years ${ }^{[7]}$ Fresh chicory typically contains $68 \%$ inulin (IN), $14 \%$ sucrose, $5 \%$ cellulose, $6 \%$ protein, $4 \%$ ash, and $3 \%$ other compounds, while dried chicory contains approximately $98 \%$ IN and $2 \%$ other compounds. ${ }^{[8]}$ Chicory IN is a natural linear molecule of fructose with 9-(2-1) glycosidic linkages that are not digested in the upper part of the gastrointestinal tract but fermented in the cecocolon. ${ }^{[9]} \mathrm{IN}$, a naturally occurring fermentable chicory fructan, has been shown to stimulate the growth of bifidobacterium, which are regarded as beneficial strains in the colon and have been found to inhibit colon and liver carcinogenesis in laboratory animal models. ${ }^{[10]}$ IN is fermentable dietary fiber, resistant to hydrolysis by pancreatic amylase and saccharidases in the upper gastrointestinal tract. Previous studies have demonstrated that IN is produced enzymatically from sucrose and that supplementing IN to high-fat diets for 12 weeks reduced body weight and serum and hepatic levels of triacylglycerols in rats. ${ }^{[11]}$ IN in human nutrition is noted for its prebiotic effect, that is, the specific stimulation of growth and/or activity of a limited number of colonic bacteria beneficial to the host, as well as its inhibition in growth of pathogens and harmful microorganisms. ${ }^{121}$ The combination of prebiotics and probiotics has given rise to so-called "synbiotics", with promising healthy properties. ${ }^{[13]}$ Experimental data demonstrates that IN and oligofructose affect processes and parameters involved in lipid metabolism, thus producing a beneficial effect on diseases related to lipid disorders such as atherosclerosis. ${ }^{[14]}$

In light of this, this study was carried out to elucidate the effective role of IN on HCC-linked adverse effects, and to evaluate its activity as a chemo-sensitizer for CIS treatment.

\section{METHODS}

\section{Experimental animals}

This study was performed on adult male Wistar rats; weighing 120-150 g. Rats were obtained from the Institute of Ophthalmic Disease Research (Cairo, Egypt). They were housed in stainless steel cages in an automatically illuminated and thermally controlled room (12 h light/dark cycle at $22-25^{\circ} \mathrm{C}$ ) at the Animal House, Faculty of Science, Mansoura University, Mansoura, Egypt. Rats were permitted an adequate standard diet (60\% ground corn meal, $15 \%$ round beans, $10 \%$ bran, $10 \%$ corn oil, $3 \%$ casein, $1 \%$ mineral mixture, and $1 \%$ vitamin mixture) purchased from Meladco Feed Company (Aubor City, Cairo, Egypt), and given water ad libitum for an adaptation period of 1 week prior to the experimental work. This experimental study was approved by review board of Mansoura University.

\section{Chemicals}

Thioacetamide (TAA) and chicory extract (IN) were purchased from Sigma Chemical Co. (St. Louis, MO, USA). CIS was purchased from Tarshouby Pharmacy (Mansoura, Egypt).

\section{Study design}

After the acclimation period, rats were divided into five groups (6 rats each). The first group was a normal control group fed a normal diet without any treatment. The second group consisted of normal rats fed a normal diet while receiving TAA daily in drinking water at a dose of $200 \mathrm{mg} / \mathrm{kg}$ b.w for 4 months. ${ }^{[15]}$ The third group consisted of normal rats fed a normal diet receiving CIS (7.5 mg/kg b.w) as a single intraperitoneal dose in addition to TAA for 4 months. ${ }^{[16]}$ In the fourth group, rats orally received IN $\left(10 \mathrm{mg} / \mathrm{kg}\right.$ b.w) in addition to TAA for 4 months. ${ }^{|17|}$ The fifth group of rats were administered CIS ( $7.5 \mathrm{mg} / \mathrm{kg}$ b.w) as a single intraperitoneal dose and IN orally $(10 \mathrm{mg} / \mathrm{kg}$ b.w) in addition to TAA for 4 months.

\section{Blood and liver sampling}

At the end of the experimental period, rats were sacrificed by cervical dislocation, and blood samples from each rat were collected into clean centrifuge tubes and centrifuged at 
$860 \mathrm{~g}$ for $20 \mathrm{~min}$. The separated sera were frozen at $-20{ }^{\circ} \mathrm{C}$ for further analysis. The rats were dissected and the livers were immediately excised, rinsed with ice-cold saline, blotted dry, and accurately weighed. They were then minced and homogenized in ice-cold buffered saline $(10 \% \mathrm{w} / \mathrm{v})$. The homogenates were centrifuged at $860 \mathrm{~g}$ for $10 \mathrm{~min}$ at $4{ }^{\circ} \mathrm{C}$. Finally, the supernatants were subjected to biochemical analysis. Other samples of the liver tissue were stored in $10 \%$ neutral formalin for histopathological studies.

\section{Biochemical analysis}

Total lipid, total cholesterol (TC), triglycerides (TGs), and high-density lipoprotein cholesterol (HDL-C) levels were quantified using kits supplied by Spinreact S.A. (Sant Esteve de Bas, Spain). ${ }^{[18-21]}$ Low-density lipoprotein cholesterol (LDL-C) and very low-density lipoprotein cholesterol (VLDL-C) levels were calculated according to the following equations, LDL-C $=$ TC - HDL-C $-\mathrm{TG} / 5^{[22]}$ and VLDL-C $=\mathrm{TG} / 5 .^{[23]}$

Alpha-fetoprotein (AFP) levels in serum was estimated by the method described previously through kits purchased from the Diagnostic Products Company (Los Angeles, CA, USA). ${ }^{[24]}$ Total protein, albumin, and total bilirubin levels were quantified, using kits from Bio-Diagnostic Co., (Dokki, Giza, Egypt) as described previously. ${ }^{[25-27]}$ Aspartate transaminase (AST) and alanine transaminase (ALT) activity was quantified using kits supplied by Spinreact S.A. (Sant Esteve de Bas, Spain) according to Young, ${ }^{[28]}$ and Belfield and Goldberg, ${ }^{[29]}$ respectively. Alkaline phosphatase (ALP) activity was quantified using kits supplied by $\mathrm{ABC}$ (Cairo, Egypt) according to Belfield and Goldberg. ${ }^{[29]}$ Creatine kinase (CK) and lactate dehydrogenase (LDH) activity was determined using kits supplied by Pinreact S.A. (Sant Esteve de Bas, Spain) according to Tietz ${ }^{[30]}$ and Goldman et al., ${ }^{[31]}$ respectively.

\section{Histopathological studies}

Liver specimens were carefully fixed in neutral formalin solution (10\%), dehydrated in ascending grades of ethanol, cleared in xylene, embedded in a paraffin wax, sectioned at 5-7 $\mu \mathrm{m}$, and stained with hematoxylin and eosin (HE). The stained sections were examined and photographed under a light microscope to detect its histopathological properties. ${ }^{\text {[32] }}$ In addition to the routine $\mathrm{H}$ and $\mathrm{E}$ stain, Masson's trichrome stains (a three-color staining protocol used in histology, where connective tissue is stained blue, nuclei are stained dark red/purple, and cytoplasm is stained red/pink) were employed for identification of collagen fibers, a good marker for various diseases such as fibrosis. ${ }^{[33]}$

\section{Statistical analysis}

Results were expressed as a mean \pm standard error of mean (SEM). Statistical significance was calculated using one-way analysis of variance followed by Duncan's multiple range test. ${ }^{\text {[34] }}$ All of the statistical analyses were carried out with the use of SPSS 12.00 software, SPSS (Hong Kong) Ltd, Quarry Bay, Hong Kong. Differences were considered significant at $P \leq 0.05$.

\section{RESULTS}

As shown in Table 1, the obtained data showed a significant increase in the lipid profile of serum (TL, TC, TG, LDL-C, and VLDL-C), AFP, and bilirubin, accompanied with significant decrease in total protein and albumin levels in HCC rats compared to the control group. In contrast, administration of IN or CIS to HCC rats showed a significant amelioration of the tested parameters, in which IN is more effective than CIS. Moreover, the results shown in Table 2, recorded a significant increase in serum enzymes (AST, ALT, ALP, LDH, and $\mathrm{CK}$ ) activity accompanied with a significant decrease in liver enzyme (AST, ALT, and ALP) activity in HCC rats compared to control group. However, administration of IN or CIS to

Table 1: Serum biochemical parameters in control and treated rat groups

\begin{tabular}{|c|c|c|c|c|c|}
\hline \multirow[t]{2}{*}{ Parameters } & \multicolumn{5}{|c|}{ Animal groups } \\
\hline & Control & TAA & TAA + CIS & TAA + IN & $\begin{array}{c}\text { TAA + IN + } \\
\text { CIS }\end{array}$ \\
\hline Total lipids (mg/dL) & $452.52 \pm 4.81^{a}$ & $599.39 \pm 6.86^{b}$ & $550.39 \pm 8.73^{c}$ & $552.18 \pm 8.54^{c}$ & $504.37 \pm 4.86^{d}$ \\
\hline Cholesterol (mg/dL) & $143.80 \pm 1.63^{\mathrm{a}}$ & $203.50 \pm 3.01^{b}$ & $157.20 \pm 2.55^{c}$ & $168.50 \pm 4.18^{d}$ & $151.10 \pm 1.74^{\mathrm{a}}$ \\
\hline Triglyceride (mg/dL) & $121.25 \pm 3.88^{a}$ & $214.30 \pm 5.49^{b}$ & $148.42 \pm 4.35^{c}$ & $180.21 \pm 1.98^{d}$ & $130.33 \pm 2.66^{\mathrm{e}}$ \\
\hline $\mathrm{HDL}-\mathrm{C}(\mathrm{mg} / \mathrm{dL})$ & $48.50 \pm 0.31^{a}$ & $23.70 \pm 1.86^{b}$ & $29.90 \pm 0.93^{c}$ & $27.90 \pm 0.74^{c}$ & $39.50 \pm 0.36^{d}$ \\
\hline VLDL-C (mg/dL) & $24.25 \pm 0.08^{a}$ & $42.86 \pm 0.49^{b}$ & $29.68 \pm 0.35^{c}$ & $36.04 \pm 0.98^{d}$ & $26.06 \pm 0.16^{\mathrm{a}}$ \\
\hline $\operatorname{AFP}(p g / m L)$ & $26.65 \pm 1.30^{\mathrm{a}}$ & $59.46 \pm 3.20^{b}$ & $42.05 \pm 1.07^{c}$ & $36.58 \pm 0.99^{d}$ & $31.84 \pm 0.65^{e}$ \\
\hline $\mathrm{Tp}(\mathrm{mg} / \mathrm{dL})$ & $9.75 \pm 0.42^{\mathrm{a}}$ & $3.95 \pm 0.60^{b}$ & $6.86 \pm 0.43^{c}$ & $7.15 \pm 0.32^{c}$ & $8.99 \pm 0.17^{a}$ \\
\hline Albumin (mg/dL) & $5.28 \pm 0.45^{\mathrm{a}}$ & $1.36 \pm 0.13^{b}$ & $2.70 \pm 1.65^{c}$ & $2.15 \pm 0.09^{c}$ & $3.81 \pm 0.26^{d}$ \\
\hline Bilirubin (mg/g) & $1.30 \pm 0.24^{a}$ & $7.95 \pm 0.92^{b}$ & $3.90 \pm 0.20^{c}$ & $3.35 \pm 0.20^{c}$ & $2.71 \pm 0.17^{c}$ \\
\hline
\end{tabular}

Results are expressed as a mean \pm SEM, with each row. Values superscripts with different letters (a-e) express the significant change at $P \leq 0.05$. Values superscripts with similar letters were non-significant. Means with different letters were significant $(P \leq 0.05, n=6)$. TAA: thioacetamide; IN: inulin; CIS: cisplatin; HDL-C: high-density lipoprotein cholesterol; LDL-C: low-density lipoprotein cholesterol; VLDL-C: very low density lipoprotein cholesterol; AFP: alpha-fetoprotein; SEM: standard error of mean 
Table 2: Serum and liver enzyme activity in control and treated rat groups

\begin{tabular}{|c|c|c|c|c|c|}
\hline \multirow[t]{2}{*}{ Parameters } & \multicolumn{5}{|c|}{ Animal groups } \\
\hline & Control & TAA & $\mathrm{TAA}+\mathrm{CIS}$ & TAA + IN & $\begin{array}{c}\mathrm{TAA}+\mathrm{IN}+ \\
\mathrm{CIS}\end{array}$ \\
\hline Serum AST (U/L) & $35.00 \pm 3.20^{\mathrm{a}}$ & $200.76 \pm 3.33^{b}$ & $123.06 \pm 1.19^{\circ}$ & $118.81 \pm 2.35^{c}$ & $86.96 \pm 2.23^{d}$ \\
\hline Serum ALT (U/L) & $56.53 \pm 1.85^{\mathrm{a}}$ & $199.00 \pm 2.89^{b}$ & $96.16 \pm 3.50^{c}$ & $77.08 \pm 1.80^{d}$ & $60.53 \pm 2.62^{\mathrm{a}}$ \\
\hline Serum ALP (U/L) & $6.44 \pm 0.30^{\mathrm{a}}$ & $11.77 \pm 0.33^{b}$ & $8.95 \pm 0.24^{c}$ & $8.14 \pm 0.19^{c}$ & $7.32 \pm 0.39^{d}$ \\
\hline Serum CK (U/L) & $241.16 \pm 0.97^{a}$ & $482.81 \pm 7.05^{b}$ & $308.91 \pm 4.39^{c}$ & $278.28 \pm 2.72^{d}$ & $259.96 \pm 1.04^{\mathrm{e}}$ \\
\hline Liver AST (U/g) & $8.94 \pm 0.16^{\mathrm{a}}$ & $0.09 \pm 0.42^{b}$ & $2.21 \pm 0.38^{c}$ & $3.96 \pm 0.15^{d}$ & $5.43 \pm 0.23^{e}$ \\
\hline Liver ALT (U/g) & $4.65 \pm 0.31^{\mathrm{a}}$ & $0.63 \pm 0.06^{b}$ & $1.55 \pm 0.15^{c}$ & $1.93 \pm 0.12^{c}$ & $2.68 \pm 0.35^{d}$ \\
\hline Liver ALP (U/g) & $50.97 \pm 1.93^{a}$ & $23.19 \pm 1.43^{b}$ & $36.11 \pm 1.29^{c}$ & $39.76 \pm 0.51^{c}$ & $48.35 \pm 1.41^{\mathrm{a}}$ \\
\hline
\end{tabular}

Results are expressed as a mean \pm SEM, with each row. Superscripts with different letters (a-e) express significant change with $P \leq 0.05$. Superscripts with similar letters were non-significant. Means with different letters were significant $(P \leq 0.05, n=6)$. TAA: thioacetamide; IN: inulin; CIS: cisplatin; AST: aspartate transaminase; ALT: alanine transaminase; ALP: alkaline phosphatase; CK: creatine kinase; LDH: lactate dehydrogenase; SEM: standard error of mean

HCC rats succeeded in inducing a significant improvement in these changes.

Histopathological examination revealed that the liver of the control group was composed of classical hepatic lobules of normal central veins lined by endothelial cells, radiating hepatic cells, and hepatic sinusoids. Hepatocytes were polyhedral in shape, with sharply defined boundaries. They had an acidophilic cytoplasm and central rounded nuclei. Frequently seen were von Kupffer cells [Figure 1, pictures C and C1]. The examination of the liver in HCC rat groups exhibited severe hepatic damages. Inflammation (lymphocytic cell infiltration), significant damage of hepatocytes, dilated congested central vein with degenerated endothelial cells, and congested blood sinusoids were observed [Figure 1, pictures HCC and HCC1]. HCC rats treated with CIS showed hepatocytes with little damage, dilated congested blood sinusoids, degenerated endothelial cells, and congested central veins [Figure 1, pictures HCC + CIS and HCC + CIS1]. However, HCC rats administered with IN showed normal hepatic lobules similar to the control group, indicating its hepatoprotective effect [Figure 1, pictures HCC + IN and HCC + IN1]. HCC rats treated with CIS and IN maintained the hepatic architecture, with minimal damage in lymphocytic cell infiltration [Figure 1, pictures HCC + CIS + IN and HCC + CIS + IN1]. These findings were evidenced by Masson's trichrome staining blue collagen fibers in hepatocytes and the central vein as a good marker for more fibrous collagen deposition, developed extensive fibrosis in the periportal area, and damaged hepatocytes in HCC rats [Figure 2, picture HCC]. Whereas, small fibrotic lesions were detected in the liver of $\mathrm{HCC}+\mathrm{IN}, \mathrm{HCC}+\mathrm{CIS}$ and HCC + IN + CIS treated groups compared to the control rat group [Figure 2].

\section{DISCUSSION}

HCC is the most common and lethal of all cancers. There exists a diversity of dietary, ${ }^{[35]}$ endogenous, and environmental ${ }^{[36]}$ stimuli that mediate hepatocarcinogenesis. Carcinogenesis may arise as a result of chemical or biological damage to normal cells in a multistep process that involves changes at the initiation level followed by promotion and progression, which leads to malignancy. ${ }^{[37]}$

The increment in the concentrations of serum total lipid, TC, TGs, and LDL-C with a reduction in the level of HDL-C in the TAA treated rats may reflect impairment of liver function, particularly in lipid metabolism. ${ }^{[38]}$ The long-term regimen of TAA led to a significant decrease of hepatic markers; total protein and albumin levels indicating acute hepatocyte damage. ${ }^{[39]}$ The alterations in lipid profiles and protein content in malignant tissues are of importance due to their effect on membrane integrity, fluidity, regulation, altered internal viscosity, and the internal chemical composition of cellular processes related to growth and cell survival. ${ }^{[40]}$ Under normal physiological conditions, the liver ensures homeostasis of lipid and lipoprotein metabolism. HCC impairs this process, leading to alterations in lipid and lipoprotein patterns. ${ }^{\mid 41]}$ Many tumor markers have been described in the hope of finding a blood test for cancer, and some have found their way into widespread but indiscriminate clinical use. Classically, a marker is synthesized by the tumor and released into circulation, but it may also be produced by normal tissue in response to invasion by cancer cells. The ideal tumor markers should be produced by the tumor cell and be readily detectable in body fluids. ${ }^{[2]}$ The continuing improvement of tumor-associated markers may help approaches in cancer treatment and diagnosis. ${ }^{[42]}$ In addition, TAA-induced abnormal lipid synthesis or defective degradation of lipids is implicated in a pathological condition like cancer. Peroxidation of lipids in biomembranes and tissues causes the leakage of these lipids into circulation and consequently leads to hyperlipidemia. Hyperlipidemia has been shown to increase the risk of metastasis in several cancers. ${ }^{[4]}$ Hepatoma is usually associated with hyperlipidemia, as well as a notable 


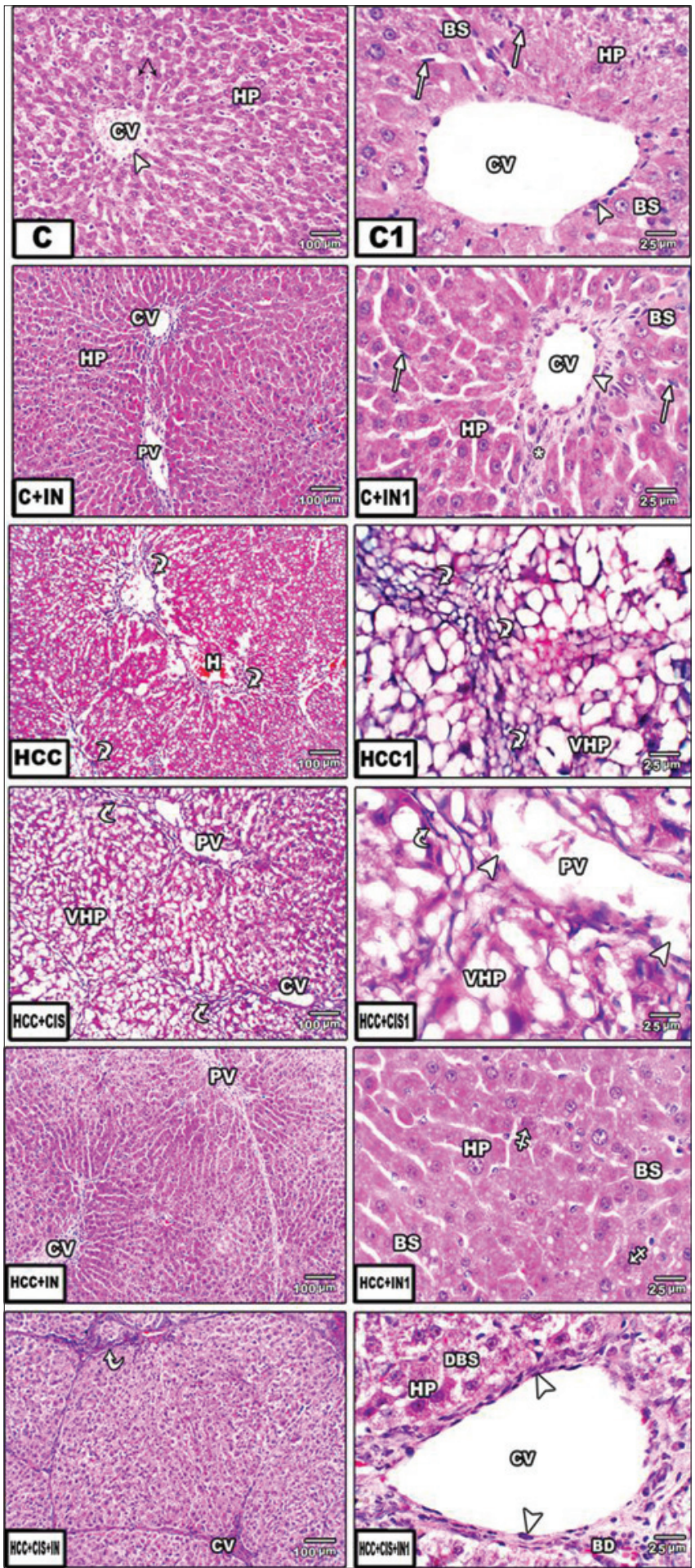

Figure 1: Photomicrographs of liver sections stained with hematoxylin and eosin ( $\mathrm{HE}$, left row $\times 100$, right row $\times 400)$. (C) Control rat showing normal hepatocytes architecture; (HCC) liver of HCC rat treated with CIS, showing damage hepatocytes with lymphocyte cells infiltration; $(\mathrm{HCC}+\mathrm{CIS})$ liver of $\mathrm{HCC}$ rat treated with $\mathrm{CIS}$ showing congested central vein and blood sinusoids; $(\mathrm{HCC}+\mathrm{IN})$ liver of $\mathrm{HCC}$ rat that received IN similar to control group; $(\mathrm{HCC}+\mathrm{CIS}+\mathrm{IN})$ liver of $\mathrm{HCC}$ treated with both $\mathrm{CIS}+\mathrm{IN}$ showing maintained hepatic architecture, with minimal damage. C: control; IN: inulin; CIS: cisplatin; HCC: hepatocellular carcinoma; CV: central vein; HP: hepatocytes; BS: blood sinusoids; VHP: vascular hepatocytes; DBS: degenerated blood sinusoids; PV: portal vein; $\mathrm{H}$ : hepatocytes; white arrow: blood sinusoids; arrowhead: Kupffer cells; black arrow: endothelial cells; *Lymphocytic cell infiltration
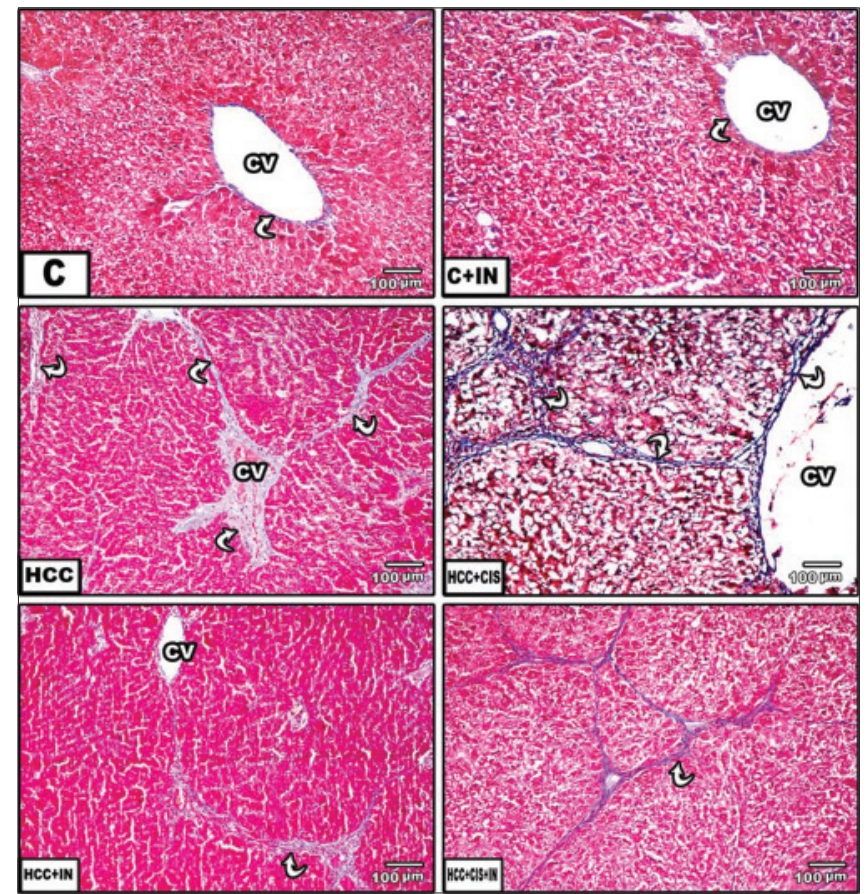

Figure 2: Photomicrographs of liver sections stained with Masson's trichrome staining $(\times 100)$. $(C)$ Liver section of control rats, fibrosis, and collagen fibers could not be seen; (HCC) liver section of HCC rat treated with thioacetamide, increased fibrosis, and blue collagen fibers are seen among hepatocytes and central vein; $(\mathrm{HCC}+\mathrm{CIS})$ liver section of $\mathrm{HCC}$ rat treated with $\mathrm{CIS}$, strands of blue collagen are less seen among hepatocytes; $(\mathrm{HCC}+\mathrm{IN})$ liver section of HCC rat that received IN, similar to the control rat group; $(\mathrm{HCC}+\mathrm{CIS}+\mathrm{IN})$ liver section of $\mathrm{HCC}$ rat treated with both $\mathrm{CIS}+\mathrm{IN}$, blue collagen fibers among hepatocytes are less seen. C: control; IN: inulin; CIS: cisplatin; HCC: hepatocellular carcinoma; $\mathrm{CV}$ : central vein; white arrow: a curved short arrow on the figure indicating blood sinusoids

decrease in the HDL fraction and an enormous increase in the VLDL and LDL fractions through resulting increase lipid peroxidation (LPO) during oxidative stress. ${ }^{[44]}$ Furthermore, albumin in the human body transports essential fatty acids from adipose tissue, otherwise known as fat, to muscle tissue; it is made by the liver. Consequently, decreased albumin levels may be associated with liver disease. ${ }^{[45]}$ Moreover, the increase in the level of AFP in HCC rats indicates an HCC. ${ }^{[46]}$ It was reported that elevated serum concentrations of AFP can be observed in rats due to exposure to hepatotoxic agents or hepatocarcinogens and are frequently associated with HCC. ${ }^{[47]}$ Its serum concentration can be used to confirm hepatocarcinoma and the diagnosis of tumor response to therapy. More than $90 \%$ of patients with hepatitis, cirrhosis, and hepatic cancer have increased serum AFP levels. ${ }^{[4]}$

Moreover, the observed alterations in serum AST, ALT, ALP, CK, and LDH activity and total bilirubin levels are good indicators for hepatic injury resulting from cellular leakage and the loss in functional integrity of the cell membrane in liver. ${ }^{[48]}$ Cellular damages are identified by increases in serum ALP, ALT, and AST levels in that these enzymes are in the cytoplasm and 
after cellular damage, enters blood circulation. ${ }^{[49]}$ This is due to the increased permeability of the plasma membrane or cellular necrosis leading to leakage of the enzymes into the blood stream. ${ }^{[50]}$

ALP is used as a specific tumor marker during diagnosis in the early detection of cancer. ${ }^{[51 \mid}$ It is involved in the transport of metabolites across cell membranes, protein synthesis, secretory activities, and glycogen metabolism. It is a membrane bound enzyme and its alteration is likely to affect membrane permeability and induces derangement in the transport of metabolites. ${ }^{\mid 52]}$ The increase of ALP in HCC rat groups found in this study may be due to the disturbance in secretion activity or due to altered gene expression. The development of a tumor results in tissue damage that leads to the release of ALP into circulation and the liver tissues of the tumor-bearing animals. Elevation of ALP is one of the signs suggesting space-occupying lesions in the liver. ${ }^{[53]}$ The rise in the activity of ALP in cancer-bearing animals may be due to a disturbance in secretory activity, the transport of metabolites, or may be due to the altered synthesis of certain enzymes in these conditions. In addition, GGT is overexpressed in tumor cells. ${ }^{[54]}$

CIS is one of the most potent chemotherapy drugs widely used for cancer treatment. It was a keystone that triggered the interest in platinum (II) and other metal-containing compounds as potential anticancer drugs. ${ }^{[55]}$ The related action of CIS activated nucleases and acid phosphatase lead not only to the breakdown of nucleic acids but also to the further dephosphorylation of mononucleotides, thereby leading to the acceleration of the processes of cell degeneration. ${ }^{[56]}$ In histology, the main hallmark of HCC is its resemblance to the normal liver both in its plate-like growth and its cytology. ${ }^{[57]}$

HCC is usually a hypervascularized tumor showing different degrees of hepatocellular differentiation, ranging from well to poorly differentiated, based on the architectural and cytologic features. Different histological patterns may be seen: (1) The trabecular pattern of growth in which tumoral hepatocytes are arranged in plates of various thickness, separated by sinusoid vascular spaces; (2) the acinar or pseudoglandular pattern showing gland-like dilatation of the canaliculi between tumor cells (lumens can contain bile) or central degeneration of trabeculae (lumen containing mainlyfibrin); and (3) the compact or solid pattern composed of thick trabeculae compressed into a compact mass that causes liver damage. ${ }^{[57]}$

Cytologically, tumoral hepatocytes are polygonal, displaying an eosinophilic granular cytoplasm, rounded nuclei, and prominent nucleoli. The importance of cell pleomorphism varies according to the degree of differentiation. Several variants of HCC are described regarding the cytological aspect of the hepatocellular proliferation. The clear cell variant is made of clear cells that may contain fat or glycogen. In the scirrhous HCC, tumor cells are generally smaller in size, showing a granular eosinophilic cytoplasm, vesicular nuclei, and conspicuous nucleoli. ${ }^{[58]}$ Sarcomatoid HCC is characterized by a sarcomatous-appearing component of spindle-shaped or giant tumor cells. ${ }^{[59]}$

In this study, IN has a prebiotic effect indicated by a decrease in the lipid profile (total lipids, cholesterol, triglyceride, LDL-C, and VLDL-C) but increased HDL-C and AFP, as well as total protein and albumin. Experimental data demonstrate that IN affect processes and parameters involved in lipid metabolism and thus produces a beneficial effect on diseases related to lipid disorders such as reductions in TG, while showing modest reductions in total, LDL-C and VLDL particles $^{[14]}$ due to the inhibition of fatty acid synthesis. ${ }^{[60]}$ The lipid-lowering action of this natural product may be mediated through the inhibition of hepatic cholesterol biosynthesis, increased faucal bile acid excretion, enhanced plasma lecithin, cholesterol acyltransferase activity, and the reduction of lipid absorption in the intestine. ${ }^{[61]}$ The IN extracted from chicory contains some fructooligosaccharides (FOSs) in addition to polysaccharides, which may provide another mechanism of action. ${ }^{[62]}$ It is well established that FOSs, besides their effect on the gastrointestinal tract, are also able to exert systemic effects by modifying the hepatic metabolism of lipids in many animal models. ${ }^{[63]}$ Colonic fermentation of FOSs results in the synthesis of short-chain fatty acids, which influence lipid metabolism in humans. ${ }^{[64]}$ In addition, IN is soluble in water and not hydrolyzed by human digestive enzymes; it is expected to behave like a soluble fiber and to have a hypolipidemic effect. ${ }^{[61,65]}$ IN lowers serum cholesterol when added to the diet of rats, and may decrease cholesterol synthesis by inhibiting hydroxymethylglutaryl-coenzyme reductase. A mechanism of action of oligofructose was associated with the modulation of de novo cholesterol synthesis by short-chain fatty acids produced by gut microflora during the fermentation process. ${ }^{[66]}$ The current study is in agreement with a previous study suggesting that chicory extract can minimize liver enzymes (AST, ALT, ALP, CK, and LDH) activity. This finding may be attributed to chicory extracts having hepatoprotective and antioxidant effects that were effective in reducing serum liver enzymes toward or even below the normal value. ${ }^{[67,68]}$ Regarding the present histopathological examination of the liver sections of HCC rats that received IN showed that the administration of IN protected rat livers from inflammation, necrosis, fibrosis, and steatosis. This was indicated by the efficiency of chicory 
extract to retain the normalization of the hepatic tissue as neither necrosis nor fatty accumulation were observed and the central vein clearly appeared. ${ }^{|69|}$

In conclusion, the current data indicated the efficacy of chicory extract (IN) supplementation as an anti-HCC in addition to its ability as a chemo-sensitizer for CIS treatment. This is mediated by intracellular pathways, involving improvement of the alterations in liver functions, as well as other aspects of HCC, the suppression of oxidative stress, and modulation of antioxidant defense mechanisms. Thus, supplementation with chicory extract may help in the safe application of cancer technology in medicine, as well as in many other aspects of everyday life. Fractionation guided evaluation could help in the development of an ideal anticancer treatment in the near future.

\section{Financial support and sponsorship}

Nil.

\section{Conflict of interest}

There is no conflict of interest.

\section{REFERENCES}

1. Zong A, Cao H, Wang F. Anticancer polysaccharides from natural resources: a review of recent research. Carbohydr Polym 2012;90:1395-410.

2. Thoppil RJ, Bishayee A. Terpenoids as potential chemopreventive and thera-peutic agents in liver cancer. World J Hepatol 2011;3:228-49.

3. Arzumanyan A, Reis HM, Feitelson MA. Pathogenic mechanisms in HBV- and HCV-associated hepatocellular carcinoma. Nat Rev Cancer 2013;13:123-35.

4. Qin W, Liu NN, Wang L, Zhou M, Ren H, Bugnard E, Liu JL, Zhang LH, Vendôme J, Hu JS, Xi XG. Characterization of biochemical properties of Bacillus subtilis RecQ helicase. J Bacteriol 2014;196:4216-28.

5. DeBerardinis RJ, Lum JJ, Hatzivassiliou G, Thompson CB. The biology of cancer: metabolic reprogramming fuels cell growth and proliferation. Cell Metab 2008;7:11-20.

6. Bauer JH, Goupil S, Garber GB, Helfand SL. An accelerated assay for the identification of lifespan-extending interventions in Drosophila melanogaster. Proc Natl Acad Sci U S A 2004;101:12980-5.

7. Jamshidzadeh A, Khoshnood MJ, Dehghani Z, Niknahad H. Hepatoprotective activity of Cichorium intybus L. leaves extract against carbon tetrachloride induced toxicity. Iran J Pharm Res 2006;5:41-6.

8. Kim M, Shin HK. The water-soluble extract of chicory reduces glucose uptake from the perfused jejunum in rats. J Nutr 1996;126:2236-42.

9. Roberfroid MB, Cumps J, Devogelaer JP. Dietary chicory inulin increases whole-body bone mineral density in growing male rats. $J$ Nutr 2002;132:3599-602.

10. Reddy BS, Hamid R, Rao CV. Effect of dietary oligofructose and inulin on colonic preneoplastic aberrant crypt foci inhibition. Carcinogenesis 1997; 18:1371-4.

11. Wada T, Sugatani J, Terada E, Ohguchi M, Miwa M. Physicochemical characterization and biological effects of inulin enzymatically synthesized from sucrose. J Agric Food Chem 2005;53:1246-53.

12. Roberfroid MB. Inulin-type fructans: functional food ingredients. J Nutr 2007; 137:S2493-502.
13. Buriti FC, Cardarelli HR, Filisetti TM, Saad SM. Synbiotic potential of fresh cream cheese supplemented with inulin and Lactobacillus paracasei in co-culture with Streptococcus thermophilus. Food Chem 2007; 104:1605-10.

14. Kaur N, Gupta AK. Applications of inulin and oligofructose in health and nutrition. J Biosci 2002;27:703-14.

15. Toyama T, Nakamura H, Harano Y, Yamauchi N, Morita A, Kirishima T, Minami M, Itoh Y, Okanoue T. PPARalpha ligands activate antioxidant enzymes and suppress hepatic fibrosis in rats. Biochem Biophys Res Commun 2004;324:697-704.

16. Yilmaz HR, Iraz M, Sogut S, Ozyurt H, Yildirim Z, Akyol O, Gergerlioglu S. The effects of erdostiene on the activity of some metabolic enzymes during cisplatin-induced nephrotoxicity in rats. Pharmacol Res 2004;50:287-90

17. Rault-Nania MH, Demougeot C, Gueux E, Berthelot A, Dzimira S, Rayssiguier Y, Rock E, Mazur A. Inulin supplementation prevents high fructose diet-induced hypertension in rats. Clin Nutr 2008;27:276-82.

18. Frings CS, Fendley TW, Dunn RT, Queen CA. Improved determination of total serum lipids by the sulfo-phospho-vanillin reaction. Clin Chem 1972;18:673-4.

19. Kayamori Y, Hatsuyama H, Tsujioka T, Nasu M, Katayama Y. Endpoint colorimetric method for assaying total cholesterol in serum with cholesterol dehydrogenase. Clin Chem 1999;45:2158-63.

20. Wahlefeld AW. Determination of serum triglycerides level. In: Bergmeyer H, editor. Methods of Enzymatic Analysis. New York: Academic Press; 1974. p. 1831-5.

21. Naito HK, Kwak YS. The evaluation of a new high density lipoprotein cholesterol (HDL-C) technology: selective separation of lipoproteins by magnetic precipitation. Clin Chem 1995;41:S135.

22. Ahmadi SA, Boroumand MA, Gohari-Moghaddam K, Tajik P, Dibaj SM. The impact of low serum triglyceride on LDL-cholesterol estimation. Arch Iran Med 2008;11:318-21.

23. Satheesh MA, Pari L. Effect of pterostilbene on lipids and lipid profiles in streptozotocin-nicotinamide induced type 2 diabetes mellitus. $J$ Appl Biomed 2008;6:31-7.

24. Acosta AA. Direct immunoenzymatic determination of AFP in serum or plasma. J Clin Immunoassays 1983;6:41.

25. Gornall AG, Bardawill CJ, David MM. Determination of serum protein by means of the biuret reaction. J Biol Chem 1949;177:751-66.

26. Doumas BT, Watson WA, Biggs HG. Albumin standards and the measurement of serum albumin with bromcresol green. Clin Chim Acta 1971;31:87-96.

27. Walter MI, Gerade HW. An ultra micromethod for the determination of conjugated and total bilirubin in serum or plasma. Microchem $J$ 1970;15:231-43.

28. Young DS. Effects of Drugs on Clinical Laboratory Tests. 4th ed. Washington, DC: AACC Press; 2001.

29. Belfield A, Goldberg DM. Normal ranges and diagnostic value of serum 5 'nucleotidase and alkaline phosphatase activities in infancy. Arch Dis Child 1971;46:842-6.

30. Tietz NW. Clinical Guide to Laboratory Tests. $3^{\text {rd }}$ ed. Philadelphia, PA: WB Saunders Company; 1995.

31. Goldman R, Kaplan NO, Hall TC. Lactic dehydrogenase in human neoplastic tissues. Cancer Res 1964;24:389-99.

32. Drury RA, Wallington EA, Cancerson R. Carlton's Histopathological Techniques. 4th ed. Oxford, UK: Oxford University Press; 1976.

33. Sheehan D, Hrapchak B. Theory and Practice of Histotechnology. 2nd ed. Ohio: Battelle Press; 1980. p. 189-90.

34. Waller RA, Duncan DB. A Bayes rule for the symmetric multiple comparison problems. J Am Stat Assoc 1969;64:1484-503.

35. Chen B, Ning M, Yang G. Effect of paeonol on antioxidant and immune regulatory activity in hepatocellular carcinoma rats. Molecules 2012; 17:4672-83.

36. Guyton KZ, Kensler TW. Oxidative mechanisms in carcinogenesis. $\mathrm{Br}$ Med Bull 1993;49:523-44. 
37. Kalaiselvan A, Gokulakrishnan K, Anand T, Akhilesh U, Velavan S. Preventive effect of Shorea robusta bark extract against diethylnitrosamine -induced hepatocellular carcinoma in rats. Int Res $J$ Medical Sci 2013;1:2-9.

38. Ahmed MK, Saleh ME, Sayed ME, Shalaby AF. Anti-inflammatory effect of different propolis extracts in thioacetamide-induced hepatotoxicity in male rat. J Basic Appl Sci 2012;6:29-40.

39. Alshawsh MA, Abdulla MA, Ismail S, Amin ZA. Hepatoprotective effects of orthosiphon stamineus extract on thioacetamide-induced liver cirrhosis in rats. Evid Based Complement Alternat Med 2011;2011:103039.

40. Tapiero H, Ba GN, Couvreur P, Tew KD. Polyunsaturated fatty acids (PUFA) and eicosanoids in human health and pathologies. Biomed Pharmacother 2002;56:215-22.

41. Jiang HE, Li X, Zhao YX, Ferguson DK, Hueber F, Bera S, Wang YF, Zhao LC, Liu CJ, Li CS. A new insight into Cannabis sativa (Cannabaceae) utilization from 2500-year-old Yanghai Tombs, Xinjiang, China. J Ethnopharmacol 2006;108:414-22.

42. Thangaraju M, Rameshbabu J, Vasavi H, Ilanchezian S, Vinitha R, Sachanandam P. The salubrious effect of tamoxifen on serum marker enzymes, glycoproteins, and lysosomal enzymes level in breast cancer woman. Mol Cell Biochem 1998;185:85-94.

43. Sako Y, Hosoi-Tanabe S, Uchida D. Fluorescence in situ hybridization using rRNA-targeted probes for simple and rapid identification of the toxic dinoflagellates Alexandrium tamarense and Alexandrium catanella. J Phycol 2004;40:598-605.

44. Kawasaki N, Hamamoto Y, Nakajima T, Irie K, Ozawa H. Periodontal regeneration of transplanted rat molars after cryopreservation. Arch Oral Biol 2004;49:59-69.

45. Di Stefano G, Busi C, Fiume L. Floxuridine coupling with lactosaminated human albumin to increase drug efficacy on liver micrometastases. Dig Liver Dis 2002;34:439-46.

46. Ahmed MB, Hasona NA, Selemain HA. Protective effects of extract from dates (Phoenix dactylifera L.) and ascorbic acid on thioacetamide-induced hepatotoxicity in rats. Iran J Pharm Res 2008;7:193-201.

47. Maideen NM, Velayutham R, Manavalan G. Activity of prosopis cineraria against $\mathrm{N}$-nitrosodiethylamine induced liver tumors by regulating the levels of tumor marker lipid peroxidation and Antioxidants. AJPLS 2012;2:1-9.

48. Kadir FA, Kassim NM, Abdulla MA, Yehye WA. Hepatoprotective role of ethanolic extract of Vitex negundo in thioacetamide-induced liver fibrosis in male rats. Evid Based Complement Alternat Med 2013;2013:739850.

49. Minnady M, Paulraj-Dominic S, Thomas S, Subramanian S. Therapeutic role of edible Mushroom Pleurotus florida on Thioacetamide induced hepatotoxicity in rats. Int J Curr Res 2010;5:041-6.

50. Al-Attar AM. Hepatoprotective influence of Vitamin C on Thioacetamide-induced liver cirrhosis in Wistar male rats. J Pharmacol Toxicol 2011;6:218-33.

51. Kobayashi T, Kawakubo T. Prospective investigation of tumor markers and risk assessment in early cancer screening. Cancer 1994;73:1946-53.
52. Patel NH, Condron BG, Zinn K. Pair-rule expression patterns of even-skipped are found in both short- and long-germ beetles. Nature 1994;367:429-34.

53. Iqbal Z, Lateef M, Ashraf M, Jabbar A. Anthelmintic activity of Artemisia brevifolia in sheep. $J$ Ethnopharmacol 2004;93:265-68.

54. Bailey T, Berg P, Sandy C. The effect of high-performance work practices on employee earnings in the steel, apparel, and medical electronics and imaging industries. Ind Labor Relat Rev 2001;54:525-43.

55. Frezza M, Hindo S, Chen D, Davenport A, Schmitt S, Tomco D, Dou QP. Novel metals and metal complexes as platforms for cancer therapy. Curr Pharm Des 2010;16:1813-25.

56. Park MS, De Leon M, Devarajan P. Cisplatin induces apoptosis in LLC-PK1 cells via activation of mitochondrial pathways. J Am Soc Nephrol 2002;13:858-65.

57. Paradis V. Histopathology of hepatocellular carcinoma. Recent Results Cancer Res 2013;190:21-32.

58. Omata M, Peters RL, Tatter D. Sclerosing hepatic carcinoma: relationship to hypercalcemia. Liver 1981;1:33-49.

59. Kojiro M, Sugihara S, Kakizoe S, Nakashima O, Kiyomatsu K. Hepatocellular carcinoma with sarcomatous change: a special reference to the relationship with anticancer therapy. Cancer Chemother Pharmacol 1989;23 Suppl: S4-8.

60. Daubioul CA, Taper HS, De Wispelaere LD, Delzenne NM. Dietary oligofructose lessens hepatic steatosis, but does not prevent hypertriglyceridemia in obese Zucker rats. J Nutr 2000;130:1314-9.

61. Kim M, Shin HY. The water-soluble extract of chicory influences serum and liver lipid concentrations, cecal short-chain fatty acid concentrations and fecal lipid excretion in rats. South J Med 2010;103:140-6.

62. Singh RS, Singh RP. Fructooligosaccharides from inulin as prebiotics. Food Technol Biotechnol 2010;48:435-50.

63. Delzenne NM, Daubioul C, Neyrinck A, Lasa M, Taper HS. Inulin and oligofructose modulate lipid metabolism in animals: review of biochemical events and future prospects. Br J Nutr 2002;87 Suppl 2:S255-9.

64. Williams CM, Jackson KG. Inulin and oligofructose: effects on lipid metabolism from human studies. Br J Nutr 2002;87 Suppl 2:S261-4.

65. Kim M, Shin HK. The water-soluble extract of chicory influences serum and liver lipid concentrations, cecal short-chain fatty acid concentrations and fecal lipid excretion in rats. J Nutr 1998;128:1731-6.

66. Brosnahan G, Fraer M. Chronic kidney disease: whom to screen and how to treat, part 1: definition, epidemiology, and laboratory testing. South Med J 2010;103:140-6.

67. Atta AH, Elkoly TA, Mouneir SM, Kamel G, Alwabel NA, Zahe S. Hepatoprotective effect of methanol extracts of Zingiber officinale and Cichorium intybus. Indian J Pharm Sci 2010;72:564-70.

68. Hassan HA, Yousef MI. Ameliorating effect of chicory (Cichorium intybus L.)-supplemented diet against nitrosamine precursors-induced liver injury and oxidative stress in male rats. Food Chem Toxicol 2010;48:2163-9.

69. Ahmed B, Al-Howiriny TA, Siddiqui AB. Antihepatotoxic activity of seeds of Cichorium intybus. J Ethnopharmacol 2003;87:237-40. 